DOI: $10.22616 /$ j.balticsurveying.2018.011

\title{
PROBLEM OF DETERMINING A GEOID
}

\author{
Olga Pisetskaya ${ }^{1}$, Alexander Yarmolenko² \\ Belarusian State Agricultural Academy ${ }^{1}$, Novgorod State University named after \\ Yaroslav the Wise/ Belarusian State Agricultural Academy²
}

\begin{abstract}
The issue of the study of the problem of determining the geoid and quasi-geoid models is considered. Development of methods for constructing an exact geoid model using different dimensions.

Analysis of the calculation of normal heights using satellite measurements, construction of geoid and quasi-geoid models by different methods is performed.

Based on the results of the analytical review of existing methods for determining the geoid, it was proposed to use various data (geodetic heights, mixed gravity anomalies, anomalous potential) to construct this model, which allows building a model of a geoid with millimetre accuracy. The possibility of using the collocation method is considered.

The task is to develop a methodology for constructing a geoid model using a network of low density gravity points and using pure and mixed gravity anomalies, which allows us to solve the problem of finding potential by solving the Laplace equation or using wavelets.

Key words: geoid, anomalies of heights, local quasi-geoid, gravimetric network, collocation method.
\end{abstract}

\section{Introduction}

The purpose of this article is to analyze the state of the study of the problem of determining the models of a geoid and quasi-geoid on a local territory and to identify the direction of construction of an adequately accurate model.

Main article objects are as follows:

1. To study the possibilities and features of calculating the normal heights according to the results of satellite measurements.

2. To analyze the construction of geoid and quasi-geoid models using different methods.

3. To set specific tasks to solve the problem of determining a geoid by using available measurements on the earth's surface.

\section{Methodology of research and materials}

In practice, various methods of constructing geoid models are encountered: astronomical and geodesic, gravimetric; joint use of GNSS measurements and leveling networks; joint use of gravimetry and satellite altimetry; satellite gradiometry (Gofman-Vellengof, 2007).

The possibility of using one or another method depends on the availability of input data, in which all available accurate geodetic measurements can be taken. Special attention is paid to the results of satellite leveling.

\section{Discussions of results}

The heights obtained from the materials of geometric leveling refer to the system of normal heights. The result of satellite measurements are geodetic heights. Using the results of satellite leveling, the normal height is determined as the difference between the geodetic height and the height of the quasigeoid (Lazarev, Samochkin, 1980).

In (Kravchuk, 2010), a technique for calculating normal altitudes by interpolation method with reference points with known differences of geodetic and normal heights according to the results of satellite measurements without gravimetric surveys is considered.

But when moving from the general earth coordinate system to a national reference coordinate system, the problem of converting them to combined points arises. In geodetic networks there are distortions in their position caused by various causes, in addition to random errors of the points. Therefore, the calculated transformation parameters will also be burdened with such errors. In addition, it is 
necessary to take into account the error in the radius of curvature of the first vertical, which will be present in the calculated normal heights (Kravchuk, 2010).

The possibility of determining a quasi-geoid on the territory of Vietnam is being investigated in (Neiman, Fam Hoang Lan, 2010). The results of calculating the orthometric height $\left(H_{p}\right)$ based on the geopotential number $\left(C_{p}\right)$.

$$
H_{P}=\frac{C_{P}}{\bar{g}},
$$

where $\bar{g}$ denotes the average value of the modulus of gravity, obtained from geometric leveling and gravimetric measurements.

$$
\bar{g}=\frac{1}{H_{P}} \int_{L}^{(P)} g d H,
$$

where L denotes the point of intersection of the curvilinear vector line of the real gravity potential with the geoid surface,

$\mathrm{P}$ denotes a point on the earth's surface.

In this article, it is noted that the position of the vector line of a real geopotential and the value of the gravity on it can be indicated approximately, which leads to approximations of the orthometric heights, and precise calculations can be made only in the framework of a certain model of the geopotential (the normal potential $\mathrm{U}$ ), observing a number of conditions:

1) the modulus of real gravity $g$ is replaced by the modulus of normal gravity $\gamma$;

2) the point of intersection of the vector line of the normal potential with the surface of the ellipsoid is taken as the starting point;

3) the end point is selected on the same vector line so that the geopotential number remains unchanged.

Thus, in this work there is also no strict solution to the problem of heights due to the impossibility of the strict determination of $\bar{g}$.

These conditions lead to the conclusion that in order to calculate the height anomaly, it is necessary to know the normal field and the perturbing potential, as well as the potential value on the surface that is assumed to be the geoid. In this case, it is necessary that the initial data for modeling with sufficient density uniformly cover the entire Earth. If we use anomalies of heights computed from gravimetric data, we get a global quasi-geoid corresponding to the general earth ellipsoid and the level surface that best approximates the averaged topographic sea surface.

The normal height $H_{P}^{\gamma}$ can be obtained from the following formula:

$$
h_{P}=H_{P}^{\gamma}+\zeta_{P},
$$

where $h_{P}$ denotes the geodetic height determined by GPS/GLONASS,

$\zeta_{P}$ denotes gravimetric anomaly of height.

The set of points obtained by this method determines a single system of heights and is its carrier. At the same time, the leveling networks are a high-precision means of propagation of the system of normal heights relative to the whole set of points. Here, the scale factor of the heights is deformed and the displacement of the resulting local quasi-geoid relative to the corresponding global surface by a certain amount (Neiman, Fam Hoang Lan, 2010). It is noted that it is necessary to amend the geodetic heights determined relative to the reference ellipsoid, which differs from the general earth's when using this method.

The results given in (Neiman, Fam Hoang Lan, 2010) are verified under the condition of a certain correspondence between the anomalies of geometric and gravimetric altitudes, which clarifies the reference altitude surface. This correction (calibration) leads to changes in gravity anomalies, and, as 
a consequence, to changes in elevation anomalies. It should be noted that the territory of Vietnam was divided into 30 regions and each covariance model was used for each region. To determine the gravimetric anomalies, the ground values of gravity anomalies in free air were used. It is indicated that the development of gravimetry and leveling is necessary to determine a local quasi-geoid.

Work (Vu Hong Kuong, 2013) reflects the results of calculations and their accuracy characteristics with the conclusion about the expediency of using the gravitational model of EGM2008 to introduce clarity into the quasi-geoid in the study area. It should be noted that for the construction of a model of gravity anomalies in Vietnam, the results of long-term ground-based measurements of gravity on land were used (Vu Hong Kuong, 2013), in addition to the use of satellite altimetry data. The average quadratic deviation of the definition of the height of the geoid of this model was approximately $0.4 \mathrm{~m}$, which indicates the need for further research on the construction of models of the Earth's gravitational field for the territory of Vietnam. The task is to create an algorithm for calculating the pure gravity anomalies $(\Delta \mathrm{g})$ and altitude anomalies $(\zeta)$ for the study area, which will allow us to refine the model using ground and satellite measurements, as well as calculate anomalies of heights and gravity at any point by using method of interpolation (Vu Hong Kuong, 2013).

In (Ha Min Hoa, 2015), the problems of equalizing the state high-rise networks of I and II classes for obtaining a geoid model by converting the measured excesses in the difference of geopotential values $\left(d C_{i j}\right)$ in the normal gravitational field of the ellipsoid are considered:

$$
d C_{i j}=\left[\bar{\gamma}_{i j}-0.1543 \cdot 10^{-6} \bar{H}_{i j}+(g-\gamma)_{i j}\right] h_{i j}
$$

where $\bar{\gamma}_{i j}$ denotes the average value of the acceleration of normal gravity between $i$ and $j$ marks,

$\bar{H}_{i j}$ denotes the average normal height,

$(g-\gamma)_{i j}$ denotes the average value of the anomalies of gravity between $i$ and $j$ marks,

$h_{i j}$ denotes the measured excess between $i$ and $\mathrm{j}$ marks in the real gravitational field of the Earth (Ha Min Hoa, 2015).

But the measured excess is in the middle tidal system, but it should correspond to the zero tidal system, which requires the $\delta d C_{i j}$ amendment to the difference of the geopotential values of $d C_{i j}$ :

$$
\delta d C_{i j}=-0.28841\left(\sin ^{2} B_{j}-\sin ^{2} B_{i}\right)-0.00195\left(\sin ^{4} B_{j}-\sin ^{4} B_{i}\right),
$$

where $B_{i}, B_{j}$ denotes geodesic latitudes of $i$ and $j$ marks.

In this article, it is noted that when using a geoid, it is possible to increase the accuracy of a local quasi-geoid, the gravitational field of the Earth on a local territory, which will improve the state highaltitude system of the local territory (Ha Min Hoa, 2015).

Construction of a geoid model using satellite observations at the points of leveling and gravimetric networks with the known orthometric heights obtained from leveling in the materials of the article for building a geoid model on the territory of the Republic of Benin (Gosmin M. Iessuru, 2015) is considered. It is indicated that in the territory of the Republic of Benin the heights of a geoid were obtained at certain chaotically located points of the leveling network. They were required to restore the surface of the geoid to the entire territory of the country. The accuracy of such a geoid will depend on the degree of coincidence of the field of application of the mathematical dependence used and the location of the control points, the properties of the mathematical dependence, the location of the reference points, and the accuracy of the initial data (Gosmin M. Iessuru, 2015).

The solution of the problem was carried out by the method of spline approximation of a function of two variables using splines with a differential quality functional. The advantage of this method lies in sufficiently accurate results with a low density of reference points, with the exception of sharp peaks 
or dips in the restored function. The solution involved the leveling and gravimetric points (Gosmin M. Iessuru, 2015).

On the territory of the Republic of Belarus, the methodology for creating a local model of quasi-geoid heights using a geometric method based on global gravity models of the Earth with the use of satellite observations is investigated. The technique was tested on the territory of Minsk and its environs without using gravimetric data (Larionov, Rudnickaya, 2016).

In this case, the essence of the geometric method consisted in the optimal combination of dissimilar heights in order to perform the detailed elaboration and correction of the global model of quasi-geoid heights by the mean-square collocation method. The main task of collocation is the prediction of a continuous surface using discrete observations. The mathematical model used by the function represented by the equation:

$$
l=A x+t+n,
$$

where $l$ denotes is the vector of measurements,

Ax denotes parametric model,

$t$ denotes signal vector at measurement points,

$n$ denotes noise vector at the measurement points.

The algorithm of computations is implemented in the materials of the article (Larionov, Rudnickaya, 2016).

The results of the studies indicated that the calculated deviations of normal heights using this model give more accurate results relative to the same data obtained by the results of calculations using the model of EGM2008. It was experimentally established that the creation of elevation models quasigeoid on the territory of the Republic of Belarus with an accuracy corresponding to modern requirements requires a sufficiently dense network of points with known geodetic and normal heights that is impractical to perform and for the possibility of using this model it is necessary to develop a gravimetric network on the territory of the Republic (Larionov, Rudnickaya, 2016).

But there are other possible solutions of the problem for determining a geoid.

1-st task. For the simplicity of the theory of analysis, it is necessary to represent the potential not only in the form of spherical functions or their analogs (substitutes): spherical functions; basic functions of various kinds (radial, spline functions, etc. (Neiman , Sugaipova, 2016); polynomials, etc., but also in the matrix form. Assuming that the observation of gravity anomalies is performed in a discrete space, that is, if the coefficients of the expansion of the potential or another potential function in terms of spherical (spherical) functions in the form of the vector $a$ and the observation vector $g$ are given, then we can write that

$$
a=W \times g,
$$

where $\mathrm{W}$ denotes the matrix of the transformation of the vector $g$ into the vector $a$.

There must be a reverse transition

$$
g=F \times a,
$$

where $\mathrm{F}$ denotes the inverse of $\mathrm{W}$.

For example, if $g$ is the anomaly of gravity, then $a$ are the coefficients of the expansion of $\mathrm{T}$ anomalous potential according to the above-mentioned anomalies:

$$
T=a_{1} \times g_{1}+a_{2} \times g_{2}+\ldots+a_{n} \times g_{n} .
$$

At the same time, it is necessary to perform the estimation of the accuracy of the potential presented in this way. 
2-nd task. When studying the gravitational field of the Earth, there are performed the determinations of such quantities as:

- mixed anomalies;

- pure anomalies;

- differences in normal and geodetic heights;

- derivatives of gravity anomalies: components of deviations of plumb lines;

- second derivatives of the potential.

Then, having a common algorithm (7)-(9), one can express any potential function in a convenient form. A special case of such a problem is the presence of a set of points, on the part of which $\Delta g$ pure gravity anomalies are measured, and on the other part - mixed anomalies (fig. 1).

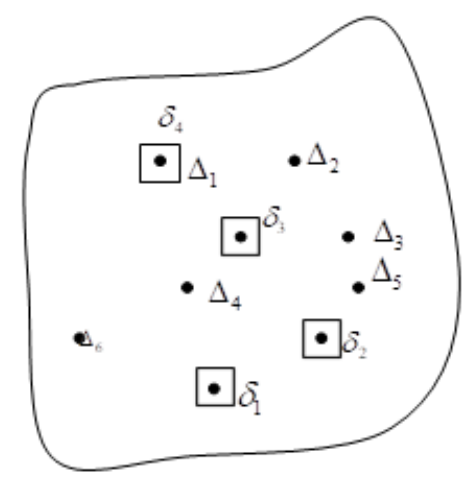

Fig. 1. Points with dimensions

As a result, on the given $N_{\Delta}$ set for points the boundary condition will be correct

$$
\frac{\partial T}{\partial h}=\Delta g,
$$

and for the points $N_{\delta}$ the boundary condition will be

$$
\frac{\partial T}{\partial h}+\frac{2 T}{R}=\delta g,
$$

where $N_{\Delta}$ denotes number of points at which pure anomalies are measured,

$N_{\delta}$ denotes number of points at which mixed anomalies are measured.

For the whole set of points

$$
N=N_{\Delta}+N_{\delta}
$$

it is necessary to solve the Laplace equation

$$
\nabla T=0,
$$

where

$$
\nabla T=\frac{\partial^{2} T}{\partial x^{2}}+\frac{\partial^{2} T}{\partial y^{2}}+\frac{\partial^{2} T}{\partial z^{2}}=0
$$

In a particular case, when the corresponding measurements are made at the same point (for example, $\delta_{4}$ and $\Delta_{1}$, Fig.1), after substitution (10) in (11) we get 


$$
\Delta g+\frac{2 T}{R}=\delta g,
$$

or

$$
\frac{2 T}{R}=\delta g-\Delta g
$$

Since the mixed anomaly is

$$
\delta g=g_{M}-\gamma_{P},
$$

and when measuring $\mathrm{g}_{\mathrm{M}}$ at the point $\mathrm{M}$, the value of $\gamma_{\mathrm{P}}$ is calculated at the point of $\mathrm{P}$,

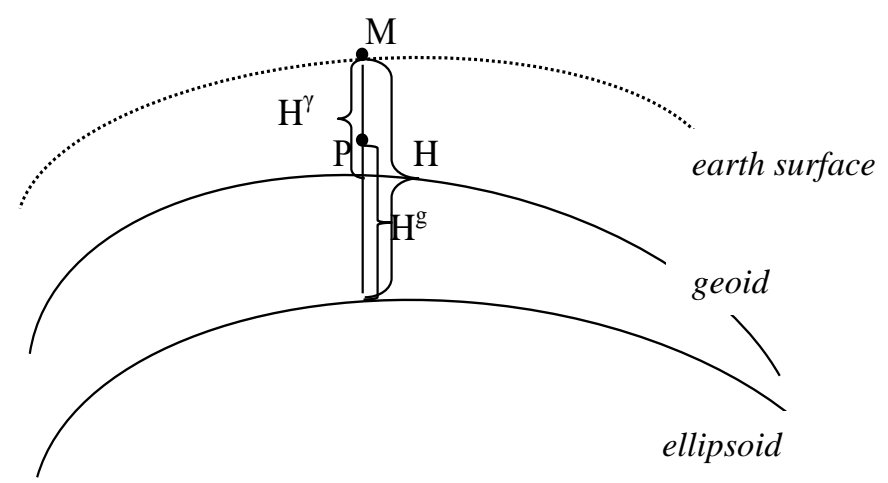

Fig. 2. Surfaces of relevance

and

$$
\Delta g=g_{M}-\gamma_{M},
$$

then, after substituting (17), (18), in (16), we have

$$
\frac{\partial T}{\partial h}=\left(g_{M}-\gamma_{P}\right)-\left(g_{M}-\gamma_{M}\right),
$$

and then

$$
\frac{\partial T}{\partial h}=-\gamma_{P}+\gamma_{M} .
$$

Then the problem of finding the potential leads to solving the Laplace equation with the boundary condition (20).

3-rd task. The task, partially solved by Russian scientists Neiman Yu. M. and Sugaipova L. S. (Neiman, Sugaipova, 2016).

The essence of the problem lies in the fact that it is possible to represent the potential (or its derivatives) not only in the form of ball (spherical) functions, but also by a combination of functions, for example, up to a certain harmonic, the expansion of the potential is carried out according to spherical functions, and after it to harmonics of an arbitrary degree - the expansion can be performed by radial basis functions, or even wavelets.

In our opinion since the combined representation of the potential is a complication of the theory, it should be constructed on the basis of the matrix approach (7) - (9).

In this case, you need to solve the following subtasks: 
1) To develop an algorithm for solving this problem;

2) To estimate the accuracy of the solution; to determine the conditions under which the accuracy of such a solution will be no lower than the standard approach for spherical functions.

The advantages of such a combined approach are proved by scientists Neiman Yu. M. and Sugaipova L. S. by the so-called frequency localization, which is clearly inherent in wavelets. For example, if we consider Table 1, the largest frequency of the wavelet expansion is inherent in the third stage of the $\mathrm{W}_{3}$ wavelet transformation.

Table 1

The wavelet decomposition

\begin{tabular}{|c|c|c|c|c|c|}
\hline № & measurements & $\mathbf{W}_{\mathbf{0}}$ & $\mathbf{W}_{\mathbf{1}}$ & $\mathbf{W}_{\mathbf{2}}$ & $\mathbf{W}_{\mathbf{3}}$ \\
\hline 1 & 4 & 4.7 & -0.5 & -1.2 & +1.0 \\
\hline 2 & 2 & 4.7 & -0.5 & -1.2 & -1.0 \\
\hline 3 & 5 & 4.7 & -0.5 & +0.8 & -0.5 \\
\hline 4 & 6 & 4.7 & -0.5 & +0.8 & +0.5 \\
\hline 5 & 7 & 4.7 & +0.5 & +0.3 & +1.5 \\
\hline 6 & 4 & 4.7 & +0.5 & +0.3 & -1.5 \\
\hline 7 & 1 & 4.7 & +0.5 & -0.2 & -4.0 \\
\hline 8 & 9 & 4.7 & +0.5 & -0.2 & +4.0 \\
\hline
\end{tabular}

But this example shows that the disadvantage of the wavelet expansion is the discrepancy between frequency localization and amplitude. Thus, in the third stage of the wavelet expansion in this example, the highest amplitudes ( 4 - according to module) of the wavelet expansion correspond to the highest frequencies. And if we remove the component of the expansion with the highest frequencies, then the largest amplitudes are also removed, which leads to a gross distortion of the original signal.

However, in Fourier series, which are actually the basis of spherical (or ball) functions, one can in principle find synchronization of the localization both in frequency and in amplitude. In Fourier series, high frequencies correspond to low amplitudes. Accordingly, the high-frequency components can be removed without a significant change in the original signal (column "Measurements").

In Fourier series, high frequencies coincide with low amplitudes. Therefore, spherical functions are convenient in application, because high degrees of expansion can be discarded, knowing that low amplitudes correspond to them, which cannot be done in wavelets.

Thereby it is necessary to solve the following subtasks:

1. The detailed development of algorithms for combined representation of a potential function based on the approach (7) - (9);

2. The search for the possibility of applying these algorithms in practice with obtaining final results of a given accuracy.

\section{Conclusions and proposals}

1. In the dissertation (Piseckaya, 2007) it is proved that at a density of pure anomalies of gravity one point per 10 square kilometers one can determine the height of a global geoid (quasi-geoid) over an ellipsoid with an accuracy of $3 \mathrm{~mm}$. But such density is necessary for the mentioned anomalies throughout the Earth, which is by now unattainable. But subject to the availability of data of geometric leveling, geodetic heights, and other precise geodetic measurements (mixed anomalies of gravity, anomalous potential, etc.) in the local territory, it is possible to determine the heights of the geoid over the ellipsoid with a given millimetric accuracy.

2. It is also necessary to generalize the problem of interpolating geoid heights over an ellipsoid using the model of EGM2008 through applying the collocation method, taking into account that inhomogeneous data are known in a limited area. For example, the anomalies of heights $\zeta$ are known in the series of the points, and the deviation of the plumb line $\xi$, $\eta$, the gravity anomalies, the excess between the points (at normal, geodetic heights), and the anomalous potential are known for the remaining part. 
3. It should be noted that the construction of a local system of heights using the collocation method is carried out by approximating linear equations, but it is possible to use polynomials (Abakushina, 2016). This operation - adaptation of EGM2008 model to the local area, called calibration, is performed on the difference between the measured and calculated heights, but it is possible to use it based on other data given at the beginning of this paragraph.

4. Due to the lack of initial data (in this case gravimetric), the use of approximating functions (spherical, ball) on a global scale can lead to distortion of results (smoothing). Therefore, according to the suggestion of Professor Yu. M. Neumann, it is necessary to develop such a technique for constructing an accurate geoid, in which gravimetric measurements made with a low density of points would not have a negative effect on the results obtained using measurements made in areas with high density of gravimetric points. In this case, other approximating functions other than spherical and ball functions may be used.

\section{References}

1. Abakushina, M., Nepoklonov, V. (2016). Ocenka tochnosti modelei gravimetricheskogo geoida v kontinentalnih raionah, Moskva. Izvestia vuzov. Geodezia I aerofotosiomka, № 6, s. 17-23 (in Russian)

2. B. Gofman-Vellengof, G. Morits (2007) Phizicheskaja geodesia. Moskva, MIIGAiK, - 426 s. (in Russian)

3. G. Lazarev, E. Samochkin (1980) Osnovi vischei geodesii. Moskva, Nedra, - 424 s. (in Russian)

4. Gosmin M. Iessuru (2015). Postroenie modeley geoida na territoriu respubliki Benin, Moskva. Izvestia vuzov. Geodezia I aerofotosiomka, № 6, s. 13-17 (in Russian)

5. Ha Min Hoa (2015). Razvitie gosudarstvennoi visotnoi sistemi Vietnama na osnove ispolzovania lokalnoi modeli geoida, Moskva. Izvestia vuzov. Geodezia I aerofotosiomka, № 2, s. 10-13 (in Russian)

6. Kravchuk, I. (2010). Osobennosti vichislenia normalnih visot po resultatam sputnikovih izmereniy, Moskva. Izvestia vuzov. Geodezia i aerofotosiomka, № 4, s. 35-40 (in Russian)

7. Larionov, A., Rudnickaya, N. (2016). Sozdanie localnoi modeli visot kvazigeoida geometricheskim metodom, Minsk. Zemlia Belarusi, № 6, s. 36-41 (in Belorussian)

8. Neiman U., Sugaipova L. (2016) Osnovi raznomashtabnoi approksimacii geopotenciala, Moskva.218 s. (in Russian)

9. Neiman, U., Fam Hoang Lan (2010). Localniy kvazigeoid izolirovannoi territorii, Moskva. Izvestia vuzov. Geodezia i aerofotosiomka, № 5, s. 31-36 (in Russian)

10. Piseckaya, O. Opredelenie figuri Zemli s ispolzovaniem GPS-izmereniy (2007), Novopolock. 124 s. (in Belorussian)

11. Vu Hong Kuong (2013). Issledovanie modelei gravitacionnogo polia Zemli po nazemnim i sputnikovim izmereniam, Moskva. Izvestia vuzov. Geodezia i aerofotosiomka, № 1, s. 20-25 (in Russian)

12. Vu Hong Kuong (2013). Resultati vichislenia anomaliy visot $i$ anomaliy sili tiagesti po sputnikovim izmereniam na territorii Vietnama, Moskva. Izvestia vuzov. Geodezia i aerofotosiomka, № 4, s. 8-13 (in Russian)

Information about the authors

Olga Pisetskaya, PhD, Dean of the Faculty of Land Management, Belarusian State Agricultural Academy, Republic of Belarus, Leninsky Boulevard, 4, Gorki, Mogilev region, +375-22-33-79644, e-mail: piseckaja@tut.by. Geodesy

Alexander Yarmolenko, Doctor of Technical Sciences, Professor, Novgorod State University named after Yaroslav the Wise/ Belarusian State Agricultural Academy, Republic of Belarus, Leninsky Boulevard, 4, Gorki, Mogilev region, 8- 911-611-47-62, e-mail: yarmolenko_alex@ mail.ru . Geodesy 